\title{
El nacimiento de la madre en el contexto de la perinatalidad ${ }^{1}$
}

\author{
Manuel Matos ${ }^{2}$ \\ PsiRelacional, Lisboa, Portugal
}

El autor articula investigaciones sobre perinatalidad, en particular de D. Stern y Bruschwiller-Stern, S. Missonier, B. Brazelton, A. Gomes Pedro, B. Cyrulnik, entre otros, con su experiencia clínica como psicoterapeuta. En su opinión, el bebé que nace, también hace nacer la madre. En circunstancias normales, las capacidades interactivas del bebé, durante la gestación, el nacimiento y la primera infancia, la responsividad de la madre y la introducción del padre en la relación, se presentan como variables esenciales para el desarrollo de la identidad materna en lo femenino. Con base en la experiencia clínica se destacan situaciones adversas, en las que la depresión y el duelo, la interrupción temprana de la simbiosis madre-bebé, la indiferencia o el rechazo, comprometen el desarrollo psíquico del bebé con consecuencias en el desarrollo de la identidad materna en lo femenino. Entre las situaciones anómalas extremas se refiere a la Cuna vacía de $M^{a}$ José Soubieux y recuerda que el bebé que muere antes de venir al mundo bloquea el acceso a la representación psíquica de lo femenino materno. Porque el bebé muere la madre no nace.

Palabras clave: Perinatalidad, competencias del bebé, identidad materna.

The author articulates investigations on perinatality, namely by D. Stern and Bruschwiller-Stern, $\mathrm{S}$. Missonier, B. Brazelton, A. Gomes Pedro, B. Cyrulnik, among others. with his clinical experience as a psychotherapist. In his opinion, the baby being born also gives birth to the mother. Under normal circumstances, the infant's interactive capacities during gestation, birth and early childhood, the responsiveness of the mother and the introduction of the father into the relationship are presented as essential variables for the development of maternal identity in the female. Based on clinical experience, it highlights adverse situations in which depression and mourning, early termination of mother-baby symbiosis, indifference or rejection, compromise the baby's psychic development with consequences on the development of maternal identity in the female. Among the extreme

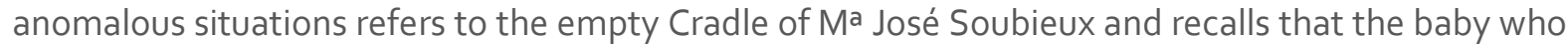
dies before coming to the world blocks access to the psychic representation of the maternal female. Because the baby dies the mother is not born.

Key Words: Perinatality, baby competences, maternal identity.

English Title: The birth of the mother in the context of perinatality

\section{Cita bibliográfica / Reference citation:}

Matos, M. (2019). El nacimiento de la madre en el contexto de la perinatalidad. Clínica e Investigación Relacional, 13 (1): 65-85. [ISSN 1988-2939] [Recuperado de www.ceir.info ] DOI: $10.21110 / 19882939.2019 .130105$

\footnotetext{
${ }^{1}$ Trabajo presentado en las II Jornadas de Psicanálise Relacional. Fac. de Psicologia, Lisboa, Mayo de 2018. Versión castellana preparada por el autor, con revisiones editoriales menores a cargo de la redacción de CelR. 2 Psicólogo clínico, psicoanalista, Presidente de PsiRelacional - Lisboa, Portugal.
} 


\section{Nota introductoria}

La línea conductora de nuestro pensamiento es que el bebé nace y hace nacer a la madre a partir del conjunto de cuidados e interacciones afectivas que necesita y la madre le proporciona, para convertirse en humano.

Como veremos a lo largo de esta exposición, el período pre y post-parto y los primeros años del bebé son los cimientos de la vida (psíquica y física).

Desde la gestación como embrión, feto o bebé y durante la primera infancia el bebé es parte activa en su propio desarrollo $y$, en ese sentido, promueve simultáneamente el nacimiento de su propia madre.

Comenzamos por el abordaje de algunos aspectos generales sobre la perinatalidad, luego haremos alusión a las capacidades interactivas del recién nacido, a las interacciones a nivel más precoz y al "nacimiento de la madre", teniendo como referencia principal a la obra de D. Stern y N. Bruschwiller-Stern "The birth of a mother" (1998). Por último vamos a articular nuestra línea de pensamiento con algunas condicionantes que interfieren en la adquisición de la identidad psíquica materna basadas en la experiencia clínica.

\section{La perinatalidad}

La perinatalidad es una nueva disciplina que involucra a pediatras, psicólogos, psicoanalistas de niños, pediatras, ginecólogos obstetras, pero también parteras, educadores de infancia, trabajadores sociales, médicos generalistas, entre otros, y que engloba la psicopatología perinatal.

Fue concebida inicialmente desde la perspectiva de la pediatría como el período que cubre del final del embarazo hasta los primeros días después del nacimiento. Pero en el sentido psicológico el concepto de perinatalidad cubre el período de desarrollo que va de la concepción al segundo año de vida y se refiere a los mecanismos psíquicos inter y transgeneracionales que van desde el deseo de embarazo, el embarazo propiamente dicho, el nacimiento y la primera infancia (o-2 / 3 años). De ahí en adelante, y según Sylvie Séguret, Bernard Golse, entre otros, responsables de Psynem, "el niño, o el futuro niño, los padres, o los futuros padres forman parte de un sistema indivisible en el que cada uno influye en el otro y recibe de ese otro influencia" teniendo en cuenta el entorno humano y ambiental.

Los técnicos de las diferentes áreas de conocimiento desarrollaron progresivamente, sobre todo a partir de 1970, su interés por la observación del recién nacido en la interacción con la madre. Las observaciones minuciosas como las de B. Brazelton (1984), D. Stern (1986), 
(1990) demostraron competencias en el recién nacido y capacidades discriminatorias que debían tenerse en cuenta en el desarrollo de la vida psíquica, y en los cuidados de prevención primaria.

Para llevar a buen término este objetivo es necesario implicar a la madre, el padre y la familia, la dimensión diádica y triádica, pero también las transmisiones inter y transgeneracionales. Gracias al desarrollo tecnológico en neonatalogía también las observaciones del recién nacido en interacción con la madre se extendieron a las observaciones intrauterinas durante la gestación.

S. Missonier (2009), (2012), autor de referencia sobre esta materia en Francia, se refiere a la perinatalidad como un proceso de desarrollo centrado en el embrión / feto / bebé en el que los padres son los actores principales, pero también la familia ampliada, la comunidad de pertenencia y la sociedad, apelando a la implicación interdisciplinaria de los técnicos cuidadores.

En su opinión, la perinatalidad constituye un marcador de fidelidad en cuanto al grado de evolución de una sociedad en la que "los medios asignados y las estrategias preventivas primarias y secundarias reflejan el reconocimiento de este período para los futuros ciudadanos", p.12.

El gran impulso dado a la perinatalidad varía según los países. En los Estados Unidos, los trabajos sobre la infancia de R. Spitz ${ }^{1}$, M. Mahler ${ }^{2}$, D. Stern y B. Brazelton antes citados, y los de D. Winnicott3, E. Bick ${ }^{4}$ y la trilogía de J. Bowlby sobre Apego, Separación y Pérdida 5 en el Reino Unido.

En Francia fueron decisivas las contribuciones de psicoanalistas de la infancia, entre ellos L. Kreisler, M. Fain y M. Soulé6 ${ }^{6}$ S. Lebovici y S. Stoleru (1983).

En Portugal, a modo de reconocimiento de la historia reciente, hago hincapié en la contribución de los psiquiatras y psicólogos infantiles portugueses, muchos de ellos formados en París, que han implementado prácticas institucionales con el énfasis en lo que se llama perinatal y articulando el conocimiento del psicoanálisis con el desarrollo psicológico del niño en la perspectiva de la relación: João dos Santos, Bairrão Ruivo, Teresa Ferreira, Emílio Salgueiro, Maria José Vidigal, son algunos de esos especialistas, sin desmerecer otros aquí no referidos.

Pero el gran impulso en el desarrollo de la perinatalidad en nuestro país es dado por A. Gomes Pedro (1982) con su tesis de doctorado con Brazelton y con la implementación de sus investigaciones en los diferentes servicios que dirigió y en las investigaciones que se desarrollan actualmente en la Fundación Brazelton / Gomes Pedro sobre vinculación, 
procesos de autoregulación emocional y sensibilización de los principales actores intervinientes en la relación precoz madre-bebé.

En la última década se ha desarrollado en la Facultad de Psicología de la Universidad de Lisboa una línea de investigación perinatal, bajo la responsabilidad de J. M. Miranda Justo (2010, 2014).

Con la colaboración de $\mathrm{M}^{a}$ E. Carvalho (2014), Chagas et al. (2015) se han adaptado instrumentos de acceso a la vida psíquica de la embarazada, especialmente sobre la ansiedad, mecanismos de defensa psíquica, diferencia en las representaciones de la embarazada sobre el bebé antes y después del nacimiento. Algunas de estas investigaciones tienen como primer autor a Maria E. Carvalho y se han desarrollado en colaboración con la Universidade Nova de Lisboa.

Para el propósito de nuestra exposición, y en coherencia con el título de la conferencia, hemos seleccionado dos aspectos importantes:

a) las capacidades sensoriales e interactivas del recién nacido;

b) las competencias precozmente observables en las interacciones madre-bebé durante la gestación.

\section{a) Sobre las capacidades interactivas del recién nacido}

Gomes Pedro investiga la capacidad interactiva del recién nacido con la madre, subraya el estado avanzado del desarrollo sensorial al nacer y la capacidad del bebé para responder a los estímulos del ambiente, o para defenderse del exceso de estimulación. En sus investigaciones es también evidente la capacidad del recién nacido para tomar iniciativas. Estas iniciativas, cuando bien interpretadas, participan en la construcción progresiva de la relación madre-bebé.

El aspecto del bebé y su propia inmadurez es de naturaleza a movilizar al adulto, y la madre en especial, en la búsqueda de respuestas integradoras de sus procesos sensoriales.

Con las investigaciones recientes pasamos del bebé, sujeto supuestamente pasivo, al bebé interactivo en gran parte actor de su propio desarrollo.

Cada uno a su tiempo y en su área, autores como H. Wallon, Ph. Malrieu, S. Freud, y el equipo de J. Piaget descubrieron y caracterizaron aspectos específicos del desarrollo psicológico del niño y dieron cuenta de la lógica específica del pensamiento peculiar infantil, especialmente en los primeros dieciocho meses de vida. 
Sin embargo la clínica psicoanalítica estableció progresivamente un nexo de causalidad entre la psicopatología del adulto y las perturbaciones del desarrollo psicológico durante la infancia en el medio familiar y más específicamente en la relación diádica y triádica.

Posteriormente M. Klein, D. Winnicott, entre muchos otros, buscaron aspectos aún más específicos ligados a dimensiones emocionales y afectivas de la vida psíquica en las diferentes edades del niño a través del juego, de las fantasías, y las relacionaron con las relaciones primarias madre-bebé; período durante el cual, acentuamos, es imposible al niño distanciarse de sus propias emociones.

En el caso de los bebés, los bebés distinguen claramente el dulce y el amargo y prefieren una solución más azucarada que insipida, como el agua, muestran capacidad auditiva, prefieren la voz humana entre otros sonidos.

A partir del $2^{\circ}$ día de vida, el bebé muestra capacidades discriminatorias a nivel del olfato y es capaz de inclinar la cabeza hacia el lado donde está una compresa empapada por la leche materna.

Desde el $4^{\circ}$ día de vida el bebé es capaz de seguir visualmente un objeto coloreado, suspende los movimientos de su cuerpo para una mejor agudeza visual y acomoda la visión a diferentes distancias del objeto.

Aunque con diferencias individuales, muchos recién nacidos son capaces de calmarse a ellos mismos, poniendo los dedos o la mano en la boca, por ejemplo. En lo que concierne a la actividad motora, algunos bebés se muestran capaces de hacer reaccionar a la madre demándandola para protegerse de estímulos sensoriales que les sean desagradables o difíciles de soportar. Por ejemplo, lloran para reclamar el silencio.

Desde las primeras horas de vida el bebé está activo en la constitución del lazo afectivo con la madre $y$, por esa vía, facilita él mismo el proceso de vinculación. Los gritos del bebé llaman la atención y constituyen una forma importante de comunicarse, contrariamente a los bebés en sufrimiento que gimen silenciosamente.

Los autores refieren trabajos de Brazelton, Stern y Tronick sobre la capacidad del bebé que alrededor de la 2a, $03^{a}$, semanas de vida buscan interacción visual con el rostro de la madre, responden a la sonrisa y manifestaciones más expresivas del rostro materno. Sin embargo, cuando no se sienten correspondidos se retraen y pueden incluso retirarse de la interacción. Destacamos que este aspecto de la retirada merece un estudio cuidado en la prevención de situaciones extremas de encapsulación autística.

A nivel de la interacción afectiva transmitida por la mirada, las entonaciones de la voz, el tono corporal, o la postura, el bebé se muestra capaz de captar el estado afectivo de la 
madre en situaciones particularmente cargadas desde el punto de vista emocional. Aunque no es capaz de hacer una lectura completa de ese estado emocional da señales de estar sorprendido cuando percibe cambios en la prosodia habitual del discurso materno.

B. Cyrulnik (2010) llama la atención sobre el valor de estos procesos sensoriales que carecen de atribución de sentido. Sin ese sentido las experiencias serán vividas como experiencias extrañas. Es el sentido dado por la madre que confiere al recién nacido capacidad de lectura de lo que él mismo siente. En el mismo sentido tenemos los trabajos de P. Fonagy 7 e Debbané ${ }^{8}$ sobre la mentalización como capacidad de la madre para intuir y dar sentido a las experiencias sin nombre durante las identificaciones primarias.

Dicho de otra forma, la articulación de la sensorialidad depende del sentido que la madre atribuye a los gestos y expresiones que van de la sonrisa al llanto, de las expresiones de confort, o incomodidad, o del tono muscular, como aquel que el bebé manifiesta cuando se anhela en los brazos que lo reciben, o cuando el bebé se yergue y desliza de los brazos en circunstancias adversas. Así sucede si el bebé siente a la madre no disponible o ansiosa.

Todos los sentidos, tacto, audición, visión, olfato, paladar, están implicados y subyacentes a las reacciones del bebé. Cuando una madre interpreta bien dirá: cómo él sabe lo que quiere. Es aquí que algunas disfunciones de la relación madre-bebé deben ser identificadas, con la ayuda de los especialistas, contribuyendo a la prevención precoz en la salud mental, que es el pilar de la salud en general.

La experiencia clínica nos muestra que los adultos que se sintieron privados de esa lectura sintónica, ajustada y en armonía, como dice D. Stern ${ }^{9}$, se muestran a veces malos intérpretes de ellos mismos, y de los demás, claro, con tendencia a evitar las emociones y minimizar la importancia de la afectividad en sus vidas y en la relación.

La filiación y la interdependencia promueven la formación identitaria en el bebé y la transformación identitaria en la mujer al convertirse en madre. Todo pasa como si la madre naciera mientras el bebé crea representaciones estables de ella como progenitora y cuidadora; lo que no siempre sucede.

Por lo tanto, en el contexto de la perinatalidad, el bebé hace nacer a la madre.

Su madre es, en cierto modo, la madre que él creó fuera de sí y en su representación mental. Con las exigencias relativas a su inmadurez, la obliga a ser madre. Cuando la madre logra ser responsiva en la experiencia de esa relación el bebé consolida progresivamente una representación mental invertida que designamos habitualmente como constancia objetal. El objeto de transición que aparece, por norma, entre el $4^{\circ}$ y el $12^{\circ}$ mes de vida es uno de 
los medios para pasar de la experiencia concreta a la experiencia subjetiva de la representación.

Desde las primeras semanas la interacción con el padre está marcada por su efecto separador de la densidad simbiótica con la madre, incluso como padre maternante. En la relación directa las actitudes del padre son más expresivas, más físicas y estimulantes. En la relación indirecta, y en conformidad con las investigaciones de R. Stoller ${ }^{10}$, el padre tiene un papel importante en la construcción de la identidad sexual del bebé a través de la relación conyugal, y a través del soporte que ofrece a la relación. Pero la relación del bebé con el padre está muy influenciada por la madre y por el lugar que ella consagra a la representación paterna en el paso progresivo de la relación diádica a la relación triádica.

Aunque las investigaciones en perinatalidad tienen como punto de incidencia la importancia de las relaciones madre-bebé, y durante los períodos más sensibles del desarrollo humano, otros trabajos amplían el estudio a la presencia real y simbólica del padre en la relación diádica. Marcel Rufo (2009), por ejemplo, pregunta: ¿será posible ser madre sin que el otro desempeñe el papel de padre?

En su libro titulado Chacun cherche son père nos dice que la paternidad es siempre del orden de la conquista y de la construcción psíquica, p.23, hecho que se presenta con más intensidad aún cuando el hombre se ve confrontado a la esterilidad, por ejemplo.

"Ser padre es transmitir mucho más allá de lo genético: una historia, valores, sueños, maneras de ver el mundo, posibilidades en el futuro. Ser padre es siempre una apuesta en el futuro ", p.29.

Ser padre tanto puede resultar del deseo de continuarse en la descendencia como corregir aspectos de su historia, en un intento de reconciliación con el pasado, buscando ser mejor padre que el padre que tuvo. No menos frecuente es el deseo de cancelar la angustia de finitud, tal como se da en la paternidad o maternidad un intento de consolidar a la pareja asignando al bebé, implícitamente, una función de unión.

Al que todo indica la única manera de superar la angustia de finitud es la de inscribirse en la transmisión. Bien vistas las cosas, también es el bebé el que hará nacer el padre.

Rufo se refiere al fenómeno de la "couvade" que según el diccionario Littré corresponde al hábito "extraño" en la reacción de los hombres que se metían en la cama cuando las mujeres estaban a punto de dar a luz, como una especie de reacción simbólica y mimética de parir. Aunque este fenómeno puede tener interpretaciones diversas, lo cierto es que algunos autores señalan cambios hormonales en el hombre a partir del primer trimestre de embarazo de su mujer. "Se trataría de una gran implicación masculina en el proceso de 
embarazo y de un fenómeno psíquico de identificación con lo femenino", p.42. Nada de extraño después de todo; ya que es la mujer embarazada que le anuncia la paternidad del hijo que tiene en el vientre. "Le père n'existe pas tout seul", p. 47.

Por su parte, J. Claude Stoloff (2007), refiriéndose a la función paterna, deja bien claro que el objeto no es la madre, ni el padre aisladamente. Para el bebé el objeto es el padre y la madre conjuntamente. Ambos constituyen una representación que debe constituir un punto de certeza. Y probablemente el más importante de todos. También Boris Cyrulnik (2016) que atribuye a la madre y al padre, cada uno a su modo y a su tiempo, la función fundamental de dar sentido a la sensorialidad del bebé, nos pregunta sobre las diferentes maneras de "comment mettre au monde un père" .

\section{b) Sobre las interacciones madre-bebé a nivel más temprano}

M.J. Soubieux y M. Soulé (2005), así como S. Missonier (2012), mencionan investigaciones con equipos multidisciplinarios a nivel de la vida fetal y la participación activa del bebé en su propio desarrollo durante la vida intrauterina.

En el cuadro de las incursiones a los períodos más remotos del bebé, aún en su estado de embrión / feto, M. Soulé y M.J. Soubieux (2009) se refieren a los estudios ecográficos y biológicos, a las técnicas de reanimación en neonatalogía que, por vía indirecta, vinieron a dar sentido a la aparición de situaciones críticas que serían de difícil comprensión sin tener en cuenta dimensiones afectivas y emocionales. Se refieren, por ejemplo, que la capacidad sensorial del feto identifica el estado emocional de la madre a través de interacciones biológicas complejas permitiendo establecer correlaciones entre perturbaciones psicosomáticas precoces del bebé y algunas dificultades psíquicas de la madre durante el embarazo, como por ejemplo aquellas que están ligadas a la muerte de un ser querido, pérdida del cónyuge o depresión.

Situaciones así pueden comprometer la construcción de las conexiones primitivas entre la madre y el bebé y devenir a partir de factores de orden psíquico, sensorial y biológico (p.1819). A modo de ejemplo evoquemos el dolor físico o psíquico de la madre en el parto que influye grandemente en la retirada relacional de la madre en un momento en que ella debe estar más presente que nunca.

En la clínica psicoanalítica hemos comprobado situaciones que permiten establecer hipótesis de conexión entre el luto de la madre durante el embarazo y la aparición de trastornos autísticos. Primando la subjetividad de estos procesos, todo pasa como si, desde 
el punto de vista fantasmático, el bebé se sintiera en la tarea imposible de hacer un duelo que la madre no logró hacer. Esta es mi hipótesis.

Las dimensiones inconscientes y fantasmáticas presiden a la inauguración del embarazo y es difícil para el niño deshacerse del papel, o de una identidad, sexual o otra, que le haya sido asignada antes de que se encuentre a sí mismo. En semejantes circunstancias la relación de objeto virtual, subjetiva, se superpondría a la relación de objeto concreta. En este sentido Missonier entiende que mientras la madre prepara una prenda de lana para el bebé que está viniendo, establece con él una relación imaginaria equivalente a la nidificación uterina. Entiende también que la relación de objeto de la mujer embarazada se sitúa entre el investimiento narcísista y el investimiento del objeto, sin perder de vista la relación que la madre tuvo con su propia madre y con las dimensiones edípicas ( $p$ 21-22).

¿Será que en estas situaciones el deseo de embarazo corresponde al deseo de maternidad? Con este propósito, Soubieux se refiere a las representaciones de la embarazada efectuadas a través de una entrevista, IRMAG, (Entrevista sobre las representaciones maternas durante el embarazo) realizadas por M. Ammaniti y al. (1999), que establecieron tres estilos de representación en la mujer embarazada: estilo integrado, estilo desinvestido, y estilo no integrado o ambivalente, capaces de influir en la relación precoz madre-bebé. Como es natural, lo que sucede desde la gestación tiene repercusiones a nivel sensorial del feto dadas sus capacidades remotas a nivel sensorial de sentir lo que la madre siente.

Todos los sistemas sensoriales están funcionando al nacer porque ya lo estaban, al menos en gran parte, durante la vida fetal.

B. Cyrulnik refiere incluso que durante el embarazo la madre inhala el olor "musc", o almiscado, específicamente masculino, del hombre que vive más cerca de ella. Olor que pasa a través de la placenta y se encuentra en el líquido amniótico al final del embarazo, permitiendo así al bebé familiarizarse con ese olor, p. 102; construyendo, por lo tanto, una imagen olfativa a partir del paladar.

La madurez del aparato coclear está preparada hacia las 28-30 semanas.

Soubieux refiere una experiencia hecha con los bebés expuestos al ruido de los aviones, cerca del aeropuerto de Osaka durante la gestación. Después del nacimiento, y cuando están a punto de dormir, los bebés que estuvieron expuestos a ese ruido durante más de 3 meses se despiertan con menos frecuencia con el ruido de otros aviones, y en otros lugares, que los bebés que no tuvieron esa experiencia durante la vida intrauterina. Se ha producido, por lo tanto, una habituación proveniente de la experiencia auditiva precoz durante el embarazo. 
Por lo demás es de conocimiento general que cuando el recién nacido está agitado se calma si se pone en contacto con el ritmo cardíaco que él aprendió en la vida intrauterina.

Cyrulnik subraya que durante el embarazo la voz de la madre se oye en el útero como un sonido grave, ya que tiene que atravesar la barrera de los pulmones y del diafragma, mientras que la voz del padre, por ejemplo, que sólo tiene que atravesar la pared abdominal para ser perceptible por el feto, se oye como un sonido más agudo, por lo que todo indica que el bebé acuático oye al padre antes de nacer.

Y viene a propósito una cita de este autor de extrema importancia en la perinatalidad: "claro que el padre penetra en el útero, pero es el observador que nombra a ese hombre como "padre", porque alguien le dijo al bebé que ese hombre era el padre. En realidad se trata del hombre de la vinculación designado por la madre. La madre lo nombra padre y diciendo eso, ella permite la penetración de ese hombre privilegiado en su útero ". (p. 105).

Más recientemente, y sobre las imágenes sonoro-musicales, como ya hemos mencionado antes, se han realizado investigaciones sobre la representación sono-musical en la embarazada en las diferentes etapas de la gestación relacionadas con la sensibilidad auditiva del feto, M. Eduarda Carvalho y J. Miranda Justo (2014).

La imagen visual se establece después de la imagen táctil, de la imagen olfativa y de la imagen sonora. El reconocimiento visual del rostro materno se establecería al cabo de un mes de vida, cuando el bebé se orienta hacia la madre desde que la ve.

Este reconocimiento es un poco controvertido, ya que el bebé tendrá que concluir que un rostro triste o enojado es lo mismo que un rostro alegre y sonriente, como bien señala Stern (1986) a propósito de los movimientos evolutivos de la interacción a la relación.

Además de lo que el bebé aprende en la vida intrauterina hay que añadir toda la influencia de la vida fantasmática de la madre sobre su bebé, como sucede en situaciones de identidad sexual atribuida en concordancia o no con la identidad sexual concreta porque el bebé se imagina antes de existir y se habla antes de ser oído, como nos dice Cyrulnik.

Hay que tener en cuenta toda la dinámica que se establece durante la gestación entre el bebé fantasmático, (dimensión inconsciente) el bebé imaginado (dimensión consciente) y el bebé real que la madre descubre al nacer con su mirada y con una sensibilidad que sólo la madre conoce.

Es dentro de este contexto de la perinatalidad que la mujer va a dar nacimiento al bebé al mismo tiempo que nace en ella misma la identidad materna. 


\section{El nacimiento de la madre}

Para D. Stern y Nadia Brusweiller-Stern (1998) lo materno es una adquisición más allá de lo femenino. Hay "nacimiento de una madre" cuando la dimensión materna emerge en lo femenino; es decir, cuando la progenitora adquiere la identidad materna lograda en función del deseo de embarazo, la vivencia del embarazo, el parto, y la atención postnatales a lo que carece el bebé mientras sea activo y participante en su propio desarrollo.

Al cuestionarse acerca del momento a partir del cual la mujer se siente madre, los autores concluyeron que la identidad materna se desarrolla por etapas: puede comenzar en cualquier momento después de que la mujer sabe que está embarazada, después del nacimiento, unos meses después de haber tenido empezando a cuidar de su bebé y cuando toma conciencia de sí misma como madre.

Dicho de otra forma, desde el punto de vista psíquico, la madre nace por etapas durante las cuales es necesario un trabajo emocional y de integración de los cambios que van a ocurrir al nivel de la relación con su propio cuerpo, de la relación con el feto en desarrollo y en los cuidados que el recién nacido exige de ella.

Todas las mujeres dicen que la experiencia de ser madre no es igual a ninguna otra en sus vidas.

Una nueva identidad emerge con emociones contradictorias y ambivalentes. La identidad materna resitúa a la mujer en la relación triangular que tuvo con la propia madre y con el padre en su infancia, en la aparición de nuevas triangulaciones; como si el triángulo se desplazara del pasado a la actualidad para garantizar la supervivencia del futuro bebé.

¿Cómo fue o no fue amada como hija?, ¿cómo será o no será capaz de amar y de cuidar como progenitora? es la gran cuestión, porque las emociones antes evitadas tendrán que ser vividas para que la intuición se desarrolle. De la madre un bebé lo espera todo. Literalmente.

Y la sociedad espera que la madre conduzca al futuro bebé a ser un ser humano. Exigencia tanto más espeluznante cuanto que en las sociedades actuales se enseña la racionalidad, el control emocional y la distancia afectiva; sabiendo que la proximidad afectiva y la intuición son de primera importancia para que la mujer se convierta en madre.

El trabajo emocional y de integración se refiere al desarrollo sensorial del bebé y al desarrollo de sus competencias, tanto antes y después del nacimiento. Según los autores convertirse en madre es un proceso en tres etapas correspondiendo cada una de ellas al desarrollo de la identidad materna. 
La primera etapa corresponde a un período de preparación que se inicia con el embarazo, mientras su cuerpo fabrica el feto, hasta el propio parto. D. Winnicott designó las reacciones maternas durante ese período de inquietud casi enfermiza, como preocupación materna primaria durante el cual emergen fantasmas arcaicos, fantasías, ilusiones, y esperanzas que pronto se enfrentarán a la realidad.

Dice la sabiduría popular que la mujer embarazada está en estado de buena esperanza. Si tenemos en cuenta toda la responsividad del feto a los estímulos venidos del exterior y a los estados emocionales de la madre, especialmente en situaciones de estrés, de ansiedad o de depresión aún en la vida intrauterina, verificamos que el bebé ya condiciona la vida de la madre. Mientras la madre genera un bebé ese bebé es un promotor de lo femenino materno

La segunda etapa del desarrollo de la identidad materna se refiere al conjunto de cuidados para con el bebé después del nacimiento, para asegurarle la supervivencia. Es una fase de construcción íntima de la conexión, o de la vinculación, si tenemos en mente los trabajos de Bowlby y sus continuadores.

Podemos decir que la dependencia absoluta del bebé va a despertar en la madre al bebé que ella fue $y$, en la mejor de las circunstancias, reavivar las fantasías de maternidad de su niñez; lo que tampoco sucede siempre. Sin el bebé la identidad materna quedaría coartada y no constituiría un añadido a lo femenino.

Los cuidados que la madre va a tener con el bebé exigen un conocimiento intuitivo que forma parte de un patrimonio sensorial, habitualmente designado de inconsciente primario no recalcado.

Autores como M. Mancia ${ }^{11}$ subrayaron en esa intuición la importancia de la memoria implícita, no verbal, o memoria sensorial. Por su parte, R. Velasco ${ }^{12}$ ha denominado conocimiento relacional implícito (CRI) a la experiencia vivida que no puede ser olvidada ni recordada. Nada debe sorprendernos si recordamos que durante el primer año de vida la comunicación madre-bebé es esencialmente prosódica, preparando al verbo.

En los años cincuenta del siglo pasado, Winnicott (1950, 1957) aconsejaba que la investigación científica respetase la comprensión intuitiva de la madre que la hace capaz de ocuparse de su bebé sin haber aprendido a hacerlo (p.34). También nos dice el mismo autor que la madre tiene un saber especializado que no puede ser enseñado ( $p .40)$.

Pero la parturienta no puede dar a luz sola. A la hora del nacimiento, que es seguramente el momento más importante de la vida humana, se conjuga la ciencia y el conocimiento implícito de base emocional y afectiva. 
Winnicott destaca la importancia del psicoanálisis en la formación de los especialistas intervinientes en el embarazo, en el parto y en los primeros tiempos de vida, porque tratan durante el embarazo y el parto con algunos trastornos somáticos que a menudo tienen un componente psíquico inconsciente. $\mathrm{Y}$ en su sencillez y claridad para exponer las cosas importantes se refiere a la madre y a la partera, que en buena verdad debería llamarse la mujer de la sabiduría, traduciendo el término francés de "sage-femme," en los siguientes términos:

- "La madre es una persona que vino al mundo, que fue bebé, que bromeó a los papás y a las mamás, que se asustó con las remodelaciones que ocurrieron en la pubertad y la adolescencia y un día, accidentalmente o no, quedó embarazada" ( $p 102$ ).

- "la sage-femme" que no es simplemente una especialista, sino también un ser humano, conoce las emociones, los saltos de humor, los momentos de excitación y de decepción, tal vez le guste en aquel momento ser la madre, o el bebé, o el padre, o bien uno o otro, (p.103).

Por lo tanto, alli está la madre para repetir una historia reciente de su infancia y la mujer de la sabiduría implicada en el nacimiento del bebé. $Y$ ambas añaden a lo femenino la componente materna.

El bebé reanuda en la progenitora a esa madre dormida. Evoco aquí, con la debida autorización, un momento de un caso de supervisión con una compañera.

Una madre desesperada le dice a un hijo de doce años: No soporto más, ya no sé qué hacer, desisto de ser madre! Otro hijo menor, de cuatro años, intervino entonces y le dijo: Madre no lo hagas. Te enseño. ¡Vas a ver que es fácil!

La tercera etapa esencial para el desarrollo de la identidad materna se refiere al reconocimiento y al estímulo hecho a la mujer por otras madres. Se trata de una necesidad de ser validada que pasa muchas veces por la triangulación madre-bebé-abuela. Mientras tanto, el bebé se da cuenta de todo lo que pasa a su alrededor, empezando, en la mejor de las circunstancias, por el amor y la disponibilidad de la madre.

Stern y Bruschweiler-Stern nos dicen que la madre que cuida durante los primeros meses a su bebé asistirá al nacimiento en ella misma de una nueva identidad de madre.

Todos conocemos los trabajos de J. Bowlby, M. Ainsworth sobre la relación entre vinculación y seguridad. En lo esencial la vinculación es un proceso de conexión psíquica que se establece durante la primera infancia en la relación diádica, pero también triádica. Los procesos de vinculación constituyen el pilar de las representaciones intrapsíquicas e 
inter-psíquicas, condicionan la relación de la persona con ella misma y con los demás, creando patrones relacionales con carácter duradero.

Estos patrones tienden a repetirse a lo largo de la vida con relativa independencia del contexto.

En situaciones particularmente complejas o de gran significado emocional, o afectivo, como es el caso del embarazo, nacimiento, lactancia y cuidados del bebé, por la enorme exigencia que tienen, se reactualizan los estilos relacionales anteriormente construidos.

Sólo para recordar, los tipos de vinculación o apego se refieren al modo como la madre y el bebé reaccionan a la separación y al reencuentro; reacciones que son reveladoras de la seguridad frente a la confianza, o inseguridad frente a la desconfianza.

En el patrón relacional de confianza la separación madre niño, durante un tiempo que varía en función de la capacidad de soportar la ausencia, no reactiva angustia de separación excesiva, y el reencuentro ocurre en un ambiente de satisfacción recíproca. Hubo nostalgia, pero la separación no cuestionó la conexión psíquica. Se dice que estamos ante un tipo de apego seguro.

Actualmente, y en general, los factores de orden social, económico y la inestabilidad a varios niveles reducen el tiempo y la calidad de la relación que el bebé necesita estar con la madre para un desarrollo armonioso. Verificamos también que es cada vez más frecuente un cierto desprendimiento del adulto en la relación primaria. En estos casos los aspectos racionales e intelectuales, disminuyen la implicación emocional y comprometen la capacidad de lectura intuitiva de la que el bebé carece.

Si tenemos como punto de referencia las situaciones clínicas de hace dos o tres décadas comparadas con las de la actualidad, son cada vez más frecuentes los patrones relacionales de inseguridad que se formaron por minimizar la importancia de la relación primaria en los cimientos de la vida ${ }^{13}$.

Otra realidad de la observación clínica es que la madre, muy a menudo, reproduce con su bebé los patrones relacionales que construyó con su propia madre, lo que nos remite a una dimensión transgeneracional de la perinatalidad. Pero no podemos generalizar, porque hay madres que fueron dadas (a otros), como si de objetos desechables se tratase, cuando eran niñas y son después excelentes madres; Aunque no establecieron vínculos afectivos con ellas, son capaces de vínculos afectivos de calidad con sus hijos.

Vale lo que estamos diciendo para regresar a Stern y Bruschweiler-Stern que describen tres tipos de apego de la madre al niño: 
- el tipo de apego descalificante, mujeres desconectadas de la experiencia de la maternidad que tuvieron, con tendencia a rechazar su propia historia, especialmente en lo que concierne a la relación con su propia madre. Aunque son capaces de evocar los acontecimientos demuestran gran distanciamiento emocional. En nuestro punto de vista, nacieron como bebés, pero es dudoso que la experiencia de la maternidad haya sido objeto de transformación identitaria;

- el tipo de apego enredado, o confuso, cuya característica principal es la falta de distancia entre la niña que fue y la madre que ahora es. Sin el debido retroceso afectivo tiene una relación fusional con su propia madre y tienden a tener ese mismo estilo de unión con sus hijos. También aquí nos preguntamos si la mujer nació como madre o si su embarazo y parto hizo de ella una progenitora que prolongó la identidad materna de su propia madre. Es el caso de que haya distancia emocional excesiva o distancia emocional insuficiente.

- el tipo de apego autónomo, que se caracteriza por la capacidad de inversión afectiva en la relación con su bebé, que mantiene con su propia madre una relación predominantemente buena y con la distancia afectiva equilibrada; siendo así capaz del retroceso suficiente para pensar y sentirse como hija y como madre. En este tipo de vínculo afectivo creo que el embarazo, el nacimiento del bebé y lo que sucede añade la identidad materna a lo femenino. Se da, en este caso, el nacimiento de la madre.

Pero hay situaciones, y bastante frecuentes, en que el nacimiento de la madre quedó incompleto, o perturbado, y otras en las que la madre no nace.

\section{Del nacimiento incompleto de la madre}

Consideramos que el nacimiento de la madre está incompleto, o ha resultado comprometido, cuando las dimensiones psicopatológicas preexistentes en la futura madre pueden afectar a la relación inicial madre-bebé, o distorsionar el proceso de su desarrollo psíquico.

Para nuestro propósito consideremos: a) la dificultad en llevar a buen término la función materna, b) la depresión y el duelo, c) la interrupción extemporánea de la simbiosis fundamental bebé-madre d) la indiferencia frente al rechazo.

a) La capacidad de llevar a buen término la función materna al mismo tiempo que el desarrollo psíquico del bebé, futuro humano, se revela cuando la madre, además de los cuidados básicos, se preocupa por el desarrollo de la vida mental de su bebé. Incluye ofrecerse como objeto estable de referencia afectiva, emocional e identificatoria; 
permitiendo al bebé la construcción de una representación de objecto estable, en el sentido que le atribuye M. Mahler.

Promover una identificación sexual sin distorsiones entre identidad sexual atribuida e identidad sexual constatada. Ser objeto de deseo, pero no objeto de satisfacción en lo que concierne al acto sexual, desarrollar la expresión de la agresividad verbal al servicio de la relación, pero no permitir que la agresividad actuada anule las diferencias y destruya la relación. Ser objeto de para-excitación y de prohibición del incesto. Desarrollar con su bebé una relación de donación y no de deuda. Y, no menos importante, exigir al padre que ocupe el lugar que debe tener en el desarrollo de la vida psíquica del bebé y en la estructuración de la vivencia edípica y narcisista, entre otras.

En la clínica, pero también en la educación, o en situaciones críticas, verificamos que cuando no se cumplen estos requisitos mínimos es muy cuestionable que a pesar del nacimiento del bebé haya habido el nacimiento de la madre. Si la función hace el órgano la maternidad hará también a la madre.

b) Las situaciones de depresión o de duelo materno provocan en la embarazada y en la parturienta una retirada afectiva que, como vimos anteriormente, se hace sentir al bebé desde la vida intrauterina y más aún en las interacciones primarias con el bebé. Una madre menos responsiva exige al bebé un mayor esfuerzo para hacerse entender para construirse, afirmar y existir. Las situaciones de depresión y duelo corresponden a pérdidas afectivas, a pérdidas de personas significativas, o ambas.

Semejantes situaciones plantean a la progenitora mucho más una situación de recibir que de dar, tanto a nivel de los afectos y de los cuidados. El resultado es, a menudo, el de una inversión implícita de roles: en lugar de la relación de donación, desarrollan con los bebés una relación de deuda. Cuando prevalece la dimensión depresiva objetiva en la madre, el niño se da cuenta de que el amor materno es precario, o condicional. Esto quiere decir que tendrá que preocuparse más por cuidar de la madre que esperar de ella la atención necesaria. Tendrá que considerarse culpable cuando no lo es, de desculpabilizar y de idealizar a la madre en contradicción con lo que siente a un nivel más profundo. Y cuando prevalecen las dimensiones de la depresión narcisista el niño opta por la línea de la hipervaloración de la madre, y en la desvalorización de sí mismo. Y más tarde hará lo mismo con otras personas. Cuando adulto sus opciones son más las de la madre que las suyas, teniendo siempre la sensación de estar por debajo de los objetivos.

En una escala de cero a veinte, y tuvo diecinueve en el examen, ¿porque no tuvo veinte? 
Un joven adulto, en un proceso avanzado de su terapia, hijo de una pareja ya divorciada hace muchos años, se quejaba al padre acerca de las actitudes de la madre en la línea de las que acabamos de describir. Oyó entonces del padre, en tono de broma: ¡Qué rayo de madre que tú has arreglado, muchacho!. Hubo nacimiento del hijo, pero no podemos afirmar que haya habido el nacimiento psíquico de lo materno; por lo menos no se reveló como tal en la vida psíquica del hijo

c) Las interrupciones extemporáneas de la simbiosis fundamental son cada vez más frecuentes. La invariante social y familiar en la actualidad es la inestabilidad, la discontinuidad, la interrupción precoz de lo que se considera fundamental, empezando por la relación primaria madre-bebé. Cuando se establece un nexo de causalidad entre las manifestaciones psicopatológicas y el historial de las relaciones significativas logramos percibir cómo la insuficiencia de tiempo y de disponibilidad para vivir la relación primaria compromete el desarrollo del niño y su futuro.

Las interrupciones relacionales tempranas producen personalidades siempre al borde de la pérdida, siempre en el límite, siempre evitando la relación, evitando las emociones y el afecto, siempre dispuestos a abandonar el proceso psicoterapéutico recién comenzado.

En nuestras consultas, los adultos, cuando se sienten en la punta del sofá, con miedo de implicarse en la relación. Están allí para quejarse, para tomarnos como testimonios de su relación, pero nunca, o raramente, dispuestos a querer articular quejas, o síntomas con el historial de las relaciones; como si cada hecho pudiera ser comprendido aisladamente. La conexión afectiva que se ha roto y el vínculo precario o interrumpido, se traducen ahora en la dificultad de establecer vínculos psíquicos entre los hechos actuales y las relaciones primarias. Estas personas se mueven preferentemente en la discontinuidad.

Un joven en psicoterapia que aguardaba contrato de trabajo quedó más satisfecho de tener un contrato por seis meses que por tiempo indeterminado. Y cuando le pregunté sobre la razón me dijo que así podía irse sin la obligación de quedarse allí. Tanto en el trabajo como en la psicoterapia, claro.

Las relaciones de compromiso exigen la capacidad de lidiar con el conflicto y la ambivalencia. En estas personas el compromiso no es su fuerte; en el proceso psicoterapéutico, cualquier acontecimiento de última hora, aunque insignificante, se superpone al compromiso verbalmente combinado y sirve de justificación de falta.

Decimos así que hubo nacimiento incompleto de la madre, cuando la relación con su bebé se pautó por la discontinuidad e interrupción precoz, sin producir constancia o permanencia objetiva y la estabilidad de las representaciones. La relación quedó fuera de 
lo necesario para que la progenitora adquiriese en relación a sí misma y en relación al hijo la dimensión psíquica de madre.

d) En las situaciones de indiferencia o rechazo del bebé por parte de la madre estamos ante una situación grave, sobre la base de la cual se organizan patologías de retiradas relacionales recíprocas, como ocurre en el autismo, en las psicosis y trastornos traumáticos precoces. Es seguramente la situación donde es más evidente el nacimiento incompleto de la madre. Ni ella se da como madre de su bebé ni el bebé logra construir una representación de lo femenino materno; con diferentes grados de gravedad.

Cuando algunos de estos pacientes recurren al proceso psicoterapéutico, o psicoanalítico, la dimensión transferencial-contratransferencial queda marcada por la indisponibilidad del terapeuta, por la dificultad de desarrollo empático con su paciente, o por la ContraIdentificación Proyectiva descrita por L. Grinberg ${ }^{14} \mathrm{Y}$ al igual que con el bebé que no pudo dar nacimiento a la madre ahora es el "analizando que no da nacimiento al analista".

Dicho de otra forma: no se establece el vínculo terapéutico, el analizando no percibe como es fundamental su "co-laboración" se instala el impasse, la resistencia recíproca y, en situaciones extremas, el precario vínculo que se estableció, se rompe.

Todo pasa como si la sala de partos fuera traspuesta al "setting" analítico, donde el analista tiene obligación de identificar distorsiones primarias y de transformarlas en vez de repetirlas.

\section{Cuando la madre no nace}

¿Y cuando la madre no nace porque el bebé muere?

Sobre este problema de la perinatalidad, Marie José Soubieux (2010) tiene un trabajo ineludible titulado: La cuna vacía. Dos imágenes recorrieron nuestro pensamiento: la de madres en la maternidad a la espera de tener el alta después del parto, retraídas, solas en su cama, sin bebé a su lado y la imagen de la madre que regresa a la casa con los brazos vacíos.

El bebé que muere antes de venir al mundo constituye un acontecimiento catastrófico, o un seísmo en la familia, una pérdida del pasado y una pérdida en el futuro, como nos dice la autora. El horror se entromete en la vida y nada más será como antes. Se deshizo una representación construida a lo largo del embarazo. En un segundo se instala el desorden y se pierde el sentido de la vida. Se hunde el presente, el abatimiento es indescriptible y sin traducción en palabras. 
El caudal de fuertes emociones contradictorias provoca la sideración en la pareja. Y la mujer que esperaba que su bebé viviera, para sentirse madre, se siente que pierde la vida.

El bebé que muere no le permite el acceso a la representación psíquica de lo femenino materno. La representación psíquica de bebé no se traduce en un hecho de vida. Y deja un duelo imposible de hacer, porque el orden natural de las cosas se perdió. Se ha invertido.

"El cuerpo de la mujer se transformó en el cuerpo de madre, pero el bebé de la parte de fuera que debía llenar el vacío dejado por el bebé de dentro desapareció" (p.31).

$\mathrm{Si}$, como decíamos inicialmente, la madre y el bebé constituyen un sistema indivisible en el que cada uno influye en el otro y recibe de ese otro la influencia, la madre no nace cuando el bebé muere.

El nacimiento de la madre como el nacimiento del hijo en el contexto de la perinatalidad obedece a dinámicas relacionales y de reciprocidad. Y son el ejemplo de lo que sucede en el psicoanálisis relacional. A pesar de las idiosincrasias de cada persona en la relación se crean espirales ascendentes de desarrollo, o de entropía cuando las circunstancias son adversas.

\section{REFERENCIAS}

BRAZELTON, T.-B. (1984). "Les compétences comportementales du nouveau-né", In Lebovici, S. Psychopathologie du bébé, Paris, Puf, 1989.

BRUSCHWEITER-STERN, N., FREELAND, A. (1998). La naissance d'une mère, trad ing. Paris, Odile Jacob, 2012.

CARVALHO, Ma-E., JUSTO, J.-M. "Construção e validação da ERSMG: Escala de representações sono-musicais na Gravidez". Revista de Psicologia, n²- Vol. 1, 2014, pp.411-418.

CARVALHO, M.-E., MIRANDA JUSTO, J.M. "The portuguese version of the placental paradigma. Questionnaire at the third trimester of pregnancy". Journal of Reproductive and Infant Psychology, 33, 5, p.478-487

CARVALHO, M.-E., MIRANDA JUSTO, J.M. "Desenho da gravidez e sensibilidade 83uncti: contributos para o estudo da psicologia da gravidez" International Journal of Developmental and Education Psychology, $\mathrm{No}_{1}$, vol. 1, 2014. P.25-34

CHAGAS, C. S., MALTEZ, P. M.L., MIRANDA, S.I.S., MIRANDA JUSTO, J.M. "The Questionnaire of the difference imaginary baby vs real baby". A new instrument for the evaluation of diferences betweeen prenatal and postnatal maternal perception after delivery. International Journal of Developmental and Education Psychology, No 2, Vol. 1, 2015 P29-38

CYRULNIK, B. Sous le signe du lien, Paris, Fayard, 2016. 
GOMES PEDRO, J.-C. (1982). Influência do contacto precoce no comportamento da díade. Lisboa: Imprensa Nacional-Casa da Moeda, 1985.

LEBOVICI, S., STOLERU, S. (1983). Le nourrisson la mère et le psychanalyste. Les 84unction8484ns precoces. Paris, Le Centurion, 1983.

MIRANDA JUSTO, J.M., MELO, V.A.L., FERREIRA, A.S. "Defense mechanisms of infertile couples VS fertile couples" International Journal of Developmental and Education Psychology, $N^{\circ} 2$, 2010, p.433-442

MIRANDA JUSTO, J.M. "Prenatal maternal psychic development and tetal 84unction84: an interacting reality". International Journal of Developmental and Education Psychology, $\mathrm{N}^{\circ} 1$, Vol. 5, 2014 p. $239-244$

MISSONIER, S. Devenir parente, maître humain. Paris, Puf, 2009.

MISSONIER, S. "Entre fureur et douleur, une passion de la haîne en perinatalité" Carnetpsy, 177, Fev.

SOUBIEUX, M.-J. Devil perinatal et travail du psychanalyste. Paris, Érès, 2010.

SOUBIEUX, M.-J., SOULÉ, M. (2005). La psychiatrie foetale, Paris, Puf, 2005.

SOUBIEUX, M.-J Le berceau vide, devil perinatal et travail du psychanalyste, Paris, Érès, 2010.

STERN, D. N. «Accordage affectif» in Houzel, D., Emmanuelli, M., Moggio, F. Dictionnaire de psychopathologie de l'enfant et de l'adolescent, Paris, Puf, 2000, pp 12-13.

STERN, D. N. (1986). Bebé-mãe : primeira relação humana, trad. Inglês, Lisboa, Slamandra, 1992.

STERN, D. N. (1990) Journal d'un bébé, trad ing. Paris, Odile Jacob, 2004.

STOLOFF, J.-C. La fonction paternelle, Paris, Edition in Press, 2007.

RUFO, M. Chacun cherche son père. Paris: Anne Carrière, 2009.

WINNICOTT, D.W. (1950-1957), Le bébé et sa mère, trad. Ing. Paris, Payot, 1992.

En este mismo número de CelR se publica online la version original portuguesa de este trabajo.

Original recibido con fecha: 26/9/2018 Revisado: 15/03/2019 Aceptado: 30/03/2019

NOTAS:

1 R. Spitz (1968) De la naissance à la parole, trad ing. Paris, Puf, 1968.

2 M. Mahler (1975) La naissance psychologique de l'être humain. Symbiose et individuation, trad ing. Paris, Puf, 1980.

3 D. Winnicott De la pédiatrie à la psychanalyse, trad. ing. Paris, Payot, 1969.

4 E. Bick, (1968) «L'expérience de la peau dans les relations objectales précoces », Revue belge de psychanalyse, 1982, 1, p.73-76. 
5 J. Bowlby (1969-1973) Apego, separação e perda, trad. ing. S. Paulo, Martins Fontes.

6 L. Kreisler, M. Fain e M. Soulé L'enfant et son corps, Paris, Puf, 1974.

7 P. Fonagy (1995) "Brincando com a realidade - I - Teoria da mente e desenvolvimento normal da realidade psíquica" Livro Anual de Psicanálise, 1996, XII, p. 11-26.

8 M. Debbané (2016) Mentaliser. Louvain-la-Neuve: De Boeck Supérieur, 2016.

9 D. Stern,. « Harmonização afectiva » in Houzel, D., Emmanuelli, M. et Moggio, F. Dicionário de psicopatología da criança e do adolescente, trad francês, Lisboa: Climepsi, 2000, p.440-441.

10 R. Stoller, (1978). Recherches sur l'identité sexuelle. Trad. ing. Paris, Galimard.

11 Mancia, M. «Mémoire implicite et inconscient précoce non refoulé : leur rôle dans le transfert et le rêve» Revue Française de Psychanalyse, 2007, 2, p.369-388

12 Velasco, R. (2006) "Memoria e conocimiento relacional implícito" Temas de psicoanalisis. www.temasdepsicoanalisis.org/memoria-y-conocimimiento-relacional-implícito, P.1-11.

13 Ashley Montagu (1986) afirma no seu livro The signifiance of the skin: A mão que embala o berço governa o mundo.

14 Grinberg, L. (1981) Psicoanálisis: aspectos teóricos y clínicos. Barcelona: Paidos, 1981, pp. 58-72. 